\title{
A Retrospective Study to Examine Healthcare Costs Related to Cardiovascular Events in Individuals with Hyperlipidemia
}

\author{
Henry J. Henk · Carly J. Paoli · Shravanthi R. Gandra
}

To view enhanced content go to www.advancesintherapy.com Received: August 28, 2015 / Published online: November 19, 2015

(C) The Author(s) 2015. This article is published with open access at Springerlink.com

\begin{abstract}
Introduction: Few studies have demonstrated the cost burden of cardiovascular events (CVEs) among patients with hyperlipidemia. The primary objective of this study was to determine the mean costs associated with CVEs among patients with hyperlipidemia by follow-up time period. Secondary objectives of this study included characterizing costs by CVE type and coronary heart disease (CHD) risk.
\end{abstract}

Methods: This retrospective cohort study used longitudinal claims to calculate payer costs according to CHD risk level and type of CVE, during several follow-up periods (acute and short-term, comprising year 1; plus years 2 and $3)$.

Electronic supplementary material The online version of this article (doi:10.1007/s12325-015-0264-7) contains supplementary material, which is available to authorized users.

H. J. Henk $(\bowtie)$

Health Economics Outcomes Research, Optum Inc., Eden Prairie, MN, USA

e-mail: henry.henk@optum.com

C. J. Paoli · S. R. Gandra

Global Health Economics, Amgen Inc., Thousand

Oaks, CA, USA
Results: There were 193,385 patients with hyperlipidemia with a CVE. Costs in the acute (30-day) period were highest $(\$ 22,404)$ driven by inpatient care (77\%). Costs remained high $(\$ 15,133$ in year 3$)$ with ambulatory care (from $14 \%$ in acute to $37 \%$ in year 3) and pharmaceutical costs (from $2 \%$ in acute to $24 \%$ in year 3) representing a greater proportion. After second and third CVEs, acute costs were lower than for the first CVE. But in the post-acute periods, costs were higher after second and third CVEs than after first CVEs. Acute costs varied considerably by type of CVE (\$9149 for transient ischemic attack to $\$ 54,251$ for coronary artery bypass graft; $P<0.001$ ), but post-acute costs were more similar across types. Costs differed by baseline CHD risk for all follow-up periods $(P<0.001)$, but less than by CVE type. As expected, patients without CVEs had significantly lower costs.

Conclusion: Among patients with hyperlipidemia, the economic burden of CVEs is substantial up to 3 years after a CVE. Costs remain high after subsequent CVEs and actually increase for non-inpatient utilization.

Funding: Amgen Inc. 
Keywords: Atherosclerosis; Cardiology; Cardiovascular disease; Coronary diseases; Healthcare costs; Hypercholesterolemia; Hyperlipidemia

\section{INTRODUCTION}

The treatment and prevention of hyperlipidemia (elevated low-density lipoprotein-C [LDL-C] levels) have been a significant public health focus for many years. Elevated LDL-C is associated with increased risk of developing coronary heart disease (CHD), the most common cause of death in the United States (US) [1, 2]. Meta-analysis of 26 clinical trials demonstrated that risk of any cardiovascular event (CVE) was reduced by $20 \%$ and mortality was reduced by $10 \%$, for every $38.7 \mathrm{mg} / \mathrm{dL}$ reduction of LDL-C [2]. Another more recent meta-analysis demonstrated among 40 trials of lipid-modifying drugs that LDL-C, but not high-density lipoprotein, levels were predictive of both primary and secondary CVEs [3]. The newest American College of Cardiology/ American Heart Association Task Force on Practice Guidelines defined the characteristics of patients who would most benefit from statin therapy to treat hyperlipidemia and prevent CVEs, including atherosclerotic cardiovascular disease (ASCVD), elevated LDL-C, diabetes, and high estimated 10-year ASCVD risk [4]. Yet, even though high LDL-C affects 71 million $(33.5 \%)$ US adults, $<50 \%$ of affected individuals receive treatment [1].

Cardiovascular disease (CVD) and stroke are major contributors of disease burden in the US [5], and globally [6]. In the US, the annual direct cost of CVD and stroke was estimated at $\$ 192.1$ billion in 2009: Approximately $\$ 86.1$ billion for inpatient stays, $\$ 46.7$ billion for outpatient or office-based visits, and $\$ 31.8$ billion for prescription drugs [7]. Costs related to CVEs include acute treatment, secondary prevention measures, recurrent CVEs, and rehabilitation [7-14]. Age, hyperlipidemia, impaired renal function, depression, and concurrent CVEs have been shown to impact costs [8, 15-19].

Previous research has been valuable in demonstrating the great cost burden of CVEs $[8,16,20-22]$, yet only one report specifically assessed cohorts of patients with hyperlipidemia. Given that adequate hyperlipidemia treatment lowers the risks associated with CVEs, it is important to obtain current cost estimates associated with CVEs. The primary objective of this study was to determine the mean costs associated with CVEs among patients with hyperlipidemia by follow-up time period. Secondary objectives of this study included characterizing costs by CVE type and CHD risk; as a reference, we provide cost estimates for a sample of non-CVE patients from the same population.

\section{METHODS}

\section{Study Design}

This was a retrospective cohort study using longitudinal administrative healthcare claims data. Healthcare costs were calculated by baseline level of CHD risk and type of CVE during several follow-up periods: Acute (days 0-30), short-term (days 31-365), first year (days 0-365), second year (days 366-730), and third year (days 731-1095). Costs of first and subsequent CVEs were also obtained. Costs were compared to patients not experiencing a CVE but with similar baseline characteristics. 


\section{Data Sources}

Data were obtained from the Optum Research Database (ORD), which contains de-identified medical and pharmacy claims data annually for approximately 14 million individuals who are enrolled in a commercial (fully insured or self-insured employer line of business) or Medicare Advantage plan. This paper reports results among commercial health plan enrollees only. The population contained within ORD is geographically diverse and fairly representative across the US, with a concentration of patients in the South. The ORD does not contain protected health information and is fully compliant with federal guidance on human subjects research, thus IRB review and approval was not required [23].

\section{Study Sample}

Subjects included members $\geq 18$ years old with hyperlipidemia identified by a claim for a hyperlipidemia drug (see Table S1 in the online supplementary material) or an International Classification of Diseases Clinical Modification 9 (ICD-9-CM) [24] code for hyperlipidemia $(272.0,272.1,272.2,272.4$, and 272.9) between January 1, 2006 and July 31, 2012 (identification period). The earliest date of a qualifying claim was the hyperlipidemia date.

Multiple types of CVEs [myocardial infarction (MI), ischemic stroke (IS), transient ischemic attack (TIA), heart failure (HF), unstable angina (UA), percutaneous coronary intervention (PCI), and coronary artery bypass graft $(\mathrm{CABG})]$ were studied. The CVEs were identified by the presence of ICD-9-CM or healthcare common procedure coding system (HCPCS) [25] codes: $\geq 1$ ICD-9-CM facility claims for hospitalizations for MI, IS, TIA, HF, or UA, or $\geq 1$ ICD-9-CM or HCPCS procedure claims for PCI or CABG (see Table S2 in the online supplementary material). For patients experiencing a CVE, their index date was the date of the first CVE following their hyperlipidemia date. The baseline period included the 12-month period prior to the index date. Follow-up was a period of variable length 30 days to 3 years, following (and including) the index date until the earlier of disenrollment, August 31, 2012, or 36 months after the index date. Continuous enrollment was required from 12 months prior to the index date.

As a reference, individuals were identified who did not have a CVE, but had similar baseline characteristics, including age, gender, health plan region, health plan type, history of chronic comorbid conditions based on ICD-9-CM diagnoses [hemorrhagic stroke, carotid artery disease, chronic renal failure, chronic obstructive pulmonary disease (COPD), asthma, mental disorders, and osteoarthritis]; number of inpatient hospitalizations in baseline period; and time between hyperlipidemia date and index date. Due to the number of variables, propensity scores (PS) were estimated for each patient using a logistic regression model. Non-CVE patients having similar PS as those experiencing a CVE were then selected. For these non-CVE patients, the index date was defined as their hyperlipidemia date plus a randomly generated number of days (to represent time between hyperlipidemia diagnosis and event 'index' date), based upon a gamma distribution. A gamma distribution was chosen because it best represented the distribution of days between hyperlipidemia date and first CVE among patients who had a CVE. 


\section{Study Measures}

\section{Demographic and Clinical Characteristics}

Patient demographics examined at the index date for all patients included age, gender, and US Census geographic region (Northeast, Midwest, South, West) [26]. Clinical characteristics examined during the baseline period included index CVE type and CHD risk level, as defined by the Adult Treatment Panel (ATP) III [27]; evidence of hemorrhagic stroke, carotid artery disease, chronic renal failure, COPD, asthma, mental disorders, or osteoarthritis; and number of all-cause inpatient hospitalizations, and emergency room and ambulatory visits (see Table S3 in the online supplementary material). The ATP III risk levels are defined as follows: high risk-any CHD or CHD risk equivalent; moderate risk-2 CHD risk factors; or low risk-0 to $1 \mathrm{CHD}$ risk factors.

For individuals with more than one CVE type, the index date was assigned based on the CVE coded in the principal or first-listed position. Second and third CVEs within 30 days following a CVE of the same type did not qualify as a new CVE. The second or third CVE date was the earliest date of the second and third qualifying CVE(s).

\section{Healthcare Costs}

Costs were reported for the follow-up periods and represented the sum of all health plan- and patient-paid amounts for all medical (ambulatory [office and outpatient hospitalization] visits, emergency room visits, inpatient hospitalization, and other services) and retail pharmacy services during the time of enrollment in the health plan. Costs prior to 2012 were adjusted to 2012 costs using the medical care component of the Consumer Price Index [28]; those incurred by other payers or managed through coordination of benefits (e.g., Medicare part A/B) were excluded.

\section{Statistical Analysis}

To estimate the health care cost and resource utilization of patients, in the same insured population, with hyperlipidemia but not experiencing a CVE we used a sample with similar baseline characteristics as patients who did experience a CVE. Given the number of baseline characteristics, we selected patients with hyperlipidemia not experiencing a CVE who had a similar propensity of having a CVE as the CVE cohort. The propensity calculation included hyperlipidemia date, index date, age, gender, health plan region, health plan type, chronic comorbid conditions (see Table S3 in the online supplementary material), number of inpatient hospitalizations in baseline period, and time to CVE. Because patients experiencing a CVE often have higher risk levels, costs within the non-CV cohorts are presented by risk level strata.

Analyses were conducted using SAS version 9.2 (SAS Institute, Inc., Cary, NC, USA) or Stata SE version 11 (StataCorp LP, College Station, TX, USA). The conventional significance level $\alpha=0.05$ was used.

\section{RESULTS}

\section{Sample Description}

The sample included 193,385 commercial enrollees with hyperlipidemia and a CVE who met study criteria. Their average $[ \pm$ standard deviation (SD)] age was $62.0( \pm 12.1)$ years, with the majority of patients being male $(62.5 \%)$, at least 55 years of age, and having high baseline CHD risk (Table 1). During the 12 months prior to their CVE, nearly $34 \%$ had been hospitalized 
Table 1 Baseline characteristics

\begin{tabular}{|c|c|}
\hline Characteristic & $\begin{array}{l}\text { Total } \\
(N=193,385)\end{array}$ \\
\hline Age (years), mean (SD) & $62.0(12.1)$ \\
\hline \multicolumn{2}{|l|}{ Age category (years) } \\
\hline $18-24$ & $179(0.09)$ \\
\hline $25-34$ & $1573(0.81)$ \\
\hline $35-44$ & $10,598(5.48)$ \\
\hline $45-54$ & $39,424(20.39)$ \\
\hline $55-64$ & $72,784(37.64)$ \\
\hline $65-74$ & $33,942(17.55)$ \\
\hline $75-84$ & $28,124(14.54)$ \\
\hline$\geq 85$ & $6761(3.50)$ \\
\hline \multicolumn{2}{|l|}{ Gender } \\
\hline Male & $120,790(62.46)$ \\
\hline Female & $72,595(37.54)$ \\
\hline \multicolumn{2}{|l|}{ Geographic region } \\
\hline Northeast & $19,530(10.10)$ \\
\hline Midwest & $48,983(25.33)$ \\
\hline South & $100,032(51.73)$ \\
\hline West & $24,797(12.82)$ \\
\hline Other & $43(0.02)$ \\
\hline \multicolumn{2}{|l|}{ Baseline clinical conditions } \\
\hline Hemorrhagic stroke & $2505(1.30)$ \\
\hline Carotid artery disease & $16,202(8.38)$ \\
\hline Chronic renal failure & $21,141(10.93)$ \\
\hline Chronic obstructive pulmonary disease & $14,212(7.35)$ \\
\hline Asthma & $17,076(8.83)$ \\
\hline Mental disorders & $62,524(32.33)$ \\
\hline Osteoarthritis & $45,594(23.58)$ \\
\hline \multicolumn{2}{|l|}{ Baseline CHD risk } \\
\hline Low risk: $0-1 \mathrm{CHD}$ risk factors & $31,307(16.19)$ \\
\hline Moderate risk: $2 \mathrm{CHD}$ risk factors & $33,512(17.33)$ \\
\hline
\end{tabular}

Table 1 continued

\begin{tabular}{ll}
\hline Characteristic & $\begin{array}{l}\text { Total } \\
(\boldsymbol{N}=\mathbf{1 9 3}, \mathbf{3 8 5})\end{array}$ \\
\hline $\begin{array}{l}\text { High risk: any CHD or CHD risk } \\
\text { equivalent }\end{array}$ & $128,566(66.48)$ \\
$\begin{array}{l}\text { Hospitalized in baseline period } \\
\text { (any cause) }\end{array}$ & $65,440(33.84)$ \\
$\begin{array}{l}\text { Emergency room visit in baseline } \\
\text { period (any cause) }\end{array}$ & $96,448(49.87)$ \\
$\begin{array}{l}\text { Number of ambulatory visits in } \\
\text { baseline period (any cause), mean } \\
(S D)\end{array}$ & $21.67(20.69)$ \\
\hline
\end{tabular}

Values are presented as $n$ (\%) unless otherwise stated $C H D$ coronary heart disease, $S D$ standard deviation

and mean baseline total costs were $\$ 25,250$ $( \pm 64,970)$. A relatively low proportion of patients had evidence of stroke, carotid artery disease, or COPD. However, mental disorders and osteoarthritis were common. The average length of follow-up after a CVE was 530 days $($ median $=456)$ with $94 \%(n=182,416)$ being enrolled during the short-term period, $57 \%$ ( $n=109,950)$ during the second year, and 33\% $(n=63,869)$ during the third year.

\section{Costs Following a CVE}

The largest total cost occurred in the first year, and most notably in the first 30 days following a CVE (acute period), driven primarily by inpatient costs at $\$ 22,404$ (comprising $77 \%$ of first year costs) while $68 \%$ of patients were hospitalized in the first 30 days (average length of stay 4.8 days). However, over time inpatient rates decreased to approximately 19\% (average length of stay 2.4-3.3 days) in the second and third years. Though costs remained high $(\$ 15,133$ in year 3$)$ over time, with inpatient 
costs accounted for a lower proportion of costs and ambulatory care (from $14 \%$ in acute to $37 \%$ in year 3) and pharmaceutical costs rose (from $2 \%$ in acute to $24 \%$ in year 3 ) (Table 2). This pattern continued for those experiencing a second $(n=84,386)$ and third CVE $(n=52,977)$, but in contrast, costs were greater in the short-term versus acute period (Fig. 1). These patterns were similar across CVE type.

\section{Costs by CVE Risk Level}

The costs for each of the follow-up periods, by risk level, are shown in Table 3 and Fig. 2. Interestingly, mean costs differed by baseline CHD risk for all time periods (overall $P<0.001$ ), but without a consistent pattern in the acute period for the CVE cohort. However, short-term, second-year, and third-year patterns were more similar (Fig. 2) between years and among risk levels, with third-year costs lower than second-year costs.

\section{Costs by Type of CVE}

Table 3 and Fig. 2 also show costs for the different event types studied. Acute costs varied considerably by type of CVE, ranging from $\$ 9149$ for TIA to $\$ 54,251$ for CABG (overall $P<0.001$ ). Although remaining significantly different (overall $P<0.001$ ) by types, costs beyond the first 30 days (short-term, second year, third year) varied less by index CVE type. In the second and third years, HF was the costliest type, while CABG was the least costly.

\section{Costs Among Patients with no CVE}

A total of 154,354 patients with hyperlipidemia but not experiencing a CVE were selected among those with a similar PS to patients experiencing a CVE. Characteristics used in the PS model were similar except a few distinctions (e.g., age and risk level) which can be attributed to the fact that patients with CVEs are typically older and at higher risk due to the inherent nature of the disease. As expected, patients without a CVE were found to have much lower costs in each of the time periods overall and within each CHD risk level (Fig. 2). Acute period costs for those with no CVE were very low compared to those with a CVE, but costs over the follow-up time periods in both groups were substantial and remained relatively steady across risk level. However, follow-up costs were double for those experiencing a CVE than those not experiencing a CVE.

\section{DISCUSSION}

The importance of this study was the focus upon the costs incurred by commercial payers following a CVE within a population of patients with hyperlipidemia, to further understand the economic burden associated with CVD among this high-risk population.

Prior claims-based studies have demonstrated recurrent hospitalizations and follow-up care are major contributors to CVE-related costs, although direct comparison between studies is hindered by differing costs captured. Roberts et al. [30] reported acute stroke-related hospitalization costs of $\$ 16,889$, plus $\$ 2203$ for additional cardiovascular-related medical services, similar to our all-cause costs for patients having stroke events. Engel-Nitzet al. [20] demonstrated patients with recurrent IS had higher hospitalization costs following subsequent stroke $(\$ 17,121)$ compared to their first stroke $(\$ 15,634)$. Among all CVE types combined in the current study, first year inpatient costs were also higher 


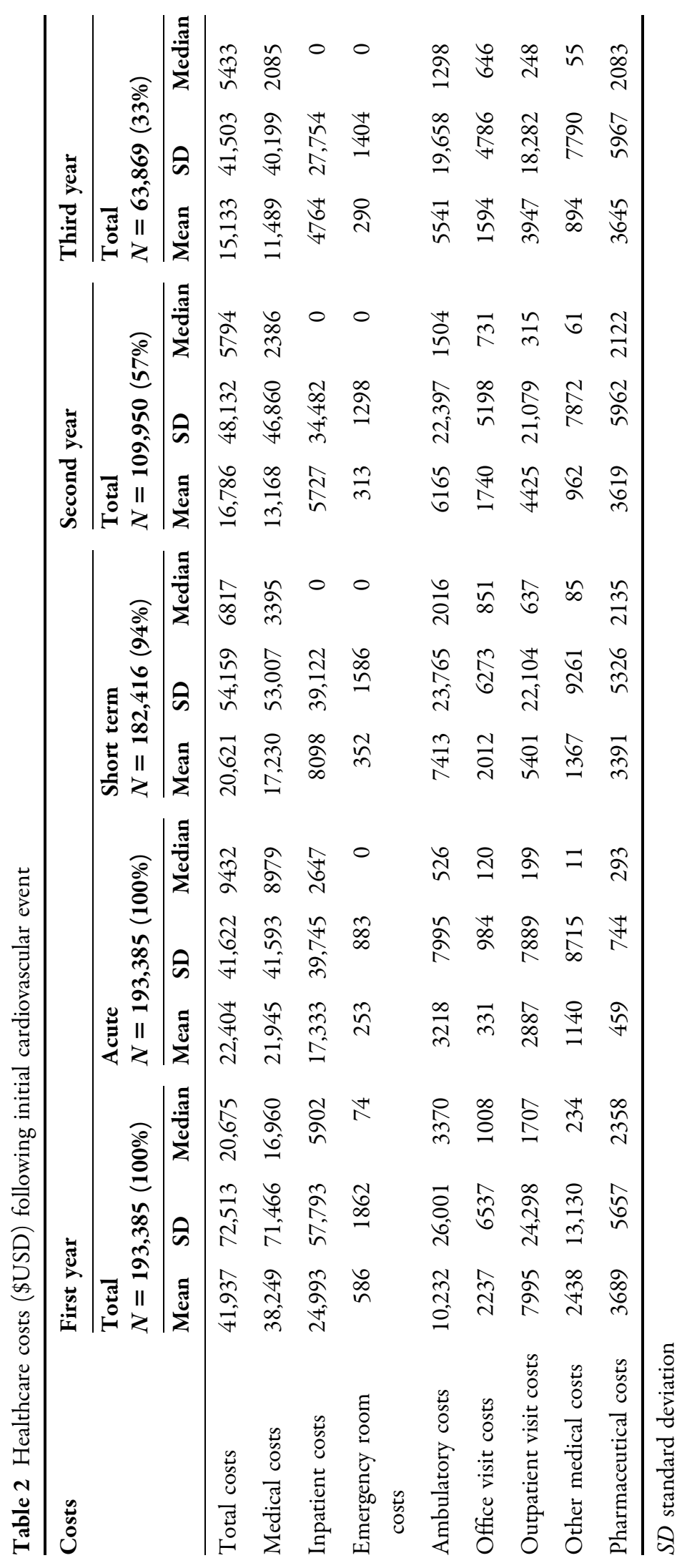




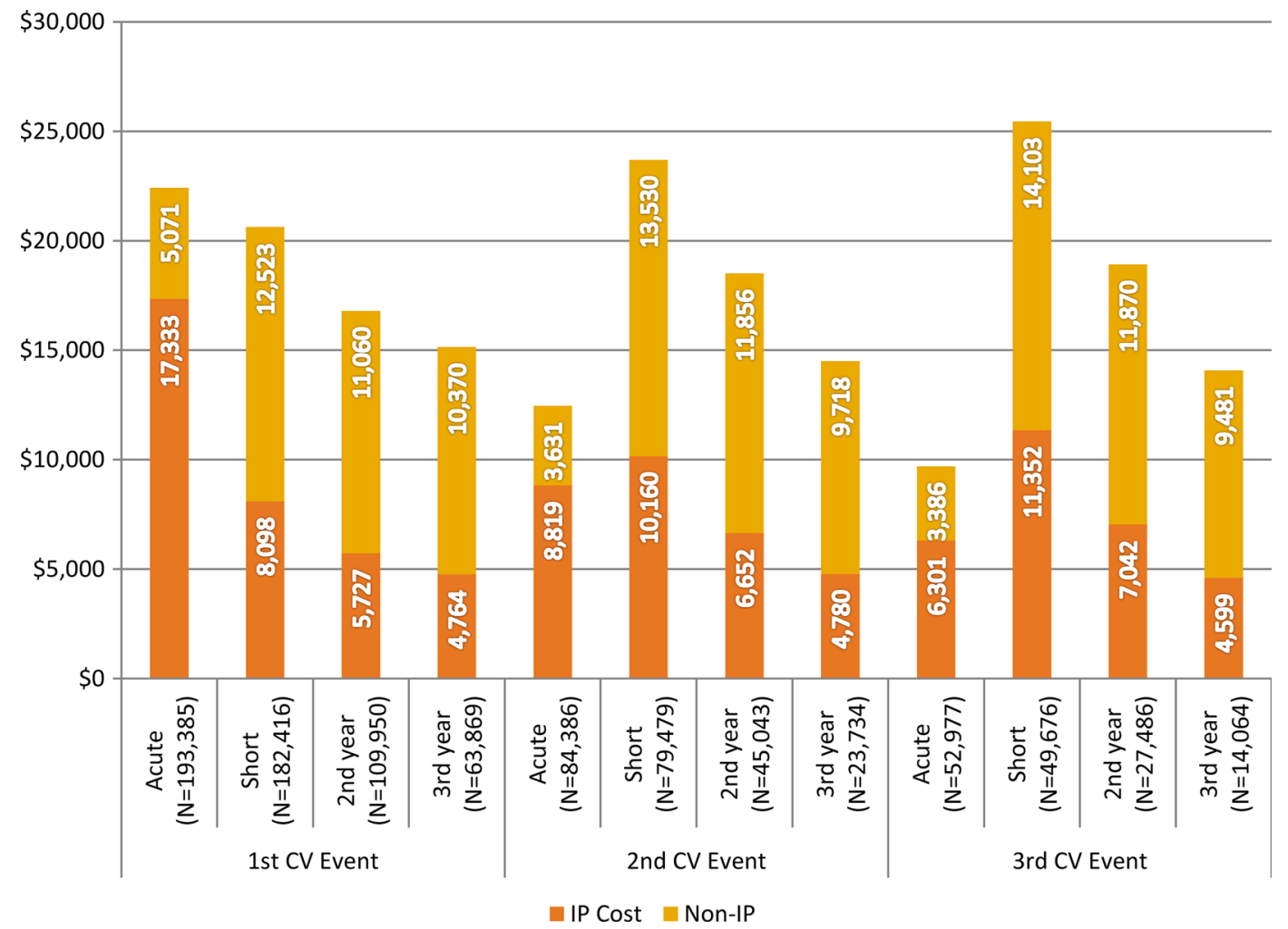

Fig. 1 Total costs (in \$USD) following first, second, and third CVE. CVE cardiovascular event, IP inpatient

for subsequent CVEs, but non-inpatient costs accounted for greater proportions. Other studies evaluated CVE costs with respect to hypertension (Duh et al. [18]) and diabetes (Straka et al. [16]) comparing costs between patients with and without CVEs. Similar to the current study, these authors found CVEs imparted significantly greater inpatient, outpatient, and prescription costs, and high continuing costs during up to three follow-up years [16]. Chapman et al. [8] conducted an observational study on costs of CVEs using dyslipidemia as one of the potential confounders in a multivariable analysis. In their study, mean total costs were at $\$ 33,563$ for the first year, compared to $\$ 41,937$ in the current study [8]. Higher estimates in the current study may be attributed to Chapman et al.'s inclusion of non-commercial insurance plans (Medicaid, Medicare, etc.), or attributing $\$ 0$ costs to disenrolling patients, as well as different patient populations/sample selection, and inflation.

A recent study by Punekar et al. [22] investigated healthcare resource utilization and costs. Some similarities exist between studies: Those with CVEs had higher healthcare costs than matched controls, and CABG and TIA events were associated with highest and lowest costs, respectively [22]. Punekar et al. [22] found total 2-year costs for their secondary prevention, high risk, and primary prevention cohorts of $\$ 46,555$, $\$ 46,739$, and $\$ 39,673$, respectively. The costs in the current study for high, moderate, and low risk categories were $\$ 42,903, \$ 38,194$, and $\$ 41,978$, respectively, for the first year post-CVE, and $\$ 18,186, \$ 14,331, \$ 13,645$, 
Table 3 Average costs (\$USD) for CVE group by risk level and type of CVE following the index CVE

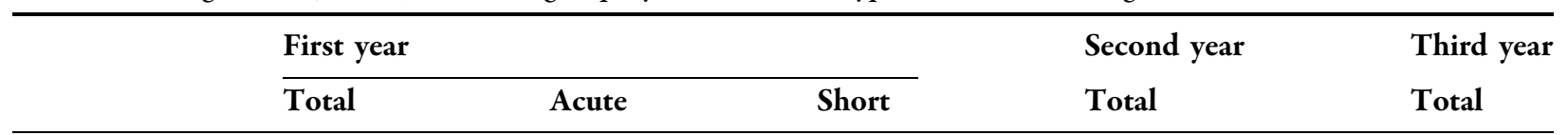

Risk level

Low risk: 0-1 CHD risk factors

$\begin{array}{llllll}N & 31,307 & 31,307 & 29,909 & 18,038 & 10,396 \\ \text { Mean } & 41,978 & 24,509 & 18,264 & 13,645 & 11,738 \\ \text { SD } & 73,773 & 44,594 & 52,401 & 42,773 & 35,603\end{array}$

Moderate risk: 2 CHD risk factors

$\begin{array}{llllll}N & 33,512 & 33,512 & 31,504 & 18,666 & 10,677 \\ \text { Mean } & 38,194 & 21,122 & 18,072 & 14,331 & 13,043 \\ \text { SD } & 66,452 & 39,406 & 48,145 & 46,880 & 37,190\end{array}$

High risk: any $\mathrm{CHD}$ or $\mathrm{CHD}$ risk equivalent

$\begin{array}{lrrrrr}N & 128,566 & 128,566 & 121,003 & 73,246 & 42,796 \\ \text { Mean } & 42,903 & 22,226 & 21,867 & 18,186 & 16,480 \\ \text { SD } & 73,676 & 41,416 & 55,992 & 49,610 & 43,728\end{array}$

Type of CVE

Myocardial infarction

$\begin{array}{llllll}N & 38,851 & 38,851 & 36,285 & 21,682 & 12,558 \\ \text { Mean } & 48,131 & 30,258 & 19,083 & 14,536 & 12,745 \\ \text { SD } & 73,948 & 48,922 & 48,000 & 39,139 & 33,825\end{array}$

Ischemic stroke

\begin{tabular}{|c|c|c|c|c|c|}
\hline$N$ & 24,757 & 24,757 & 22,920 & 12,661 & 6944 \\
\hline Mean & 39,608 & 20,086 & 20,996 & 15,072 & 13,528 \\
\hline SD & 80,497 & 45,600 & 59,176 & 43,219 & 39,748 \\
\hline \multicolumn{6}{|c|}{ Percutaneous coronary intervention } \\
\hline$N$ & 31,455 & 31,455 & 30,589 & 20,203 & 12,327 \\
\hline Mean & 39,720 & 23,539 & 16,593 & 15,228 & 14,215 \\
\hline SD & 46,733 & 22,335 & 37,426 & 34,154 & 30,601 \\
\hline
\end{tabular}

Coronary artery bypass graft

$\begin{array}{lrrrrr}N & 10,998 & 10,998 & 10,664 & 6962 & 4213 \\ \text { Mean } & 69,598 & 54,251 & 15,804 & 11,671 & 11,003 \\ \text { SD } & 71,263 & 55,042 & 37,180 & 28,822 & 34,267\end{array}$

Angina

\begin{tabular}{llllll}
$N$ & 18,970 & 18,970 & 18,349 & 11,763 & 7226 \\
\hline
\end{tabular}


Table 3 continued

\begin{tabular}{|c|c|c|c|c|c|}
\hline & \multicolumn{3}{|c|}{ First year } & \multirow{2}{*}{$\begin{array}{l}\text { Second year } \\
\text { Total }\end{array}$} & \multirow{2}{*}{$\begin{array}{l}\text { Third year } \\
\text { Total }\end{array}$} \\
\hline & Total & Acute & Short & & \\
\hline Mean & 29,069 & 14,077 & 15,465 & 14,131 & 13,971 \\
\hline SD & 47,035 & 26,364 & 35,364 & 32,062 & 32,596 \\
\hline \multicolumn{6}{|c|}{ Transient ischemic attack } \\
\hline$N$ & 17,694 & 17,694 & 16,998 & 10,429 & 6038 \\
\hline Mean & 23,089 & 9149 & 14,416 & 12,653 & 11,873 \\
\hline $\mathrm{SD}$ & 45,322 & 21,863 & 36,596 & 32,618 & 35,226 \\
\hline \multicolumn{6}{|c|}{ Heart failure } \\
\hline$N$ & 50,660 & 50,660 & 46,611 & 26,250 & 14,563 \\
\hline Mean & 45,098 & 17,644 & 29,672 & 24,860 & 21,859 \\
\hline SD & 91,161 & 44,566 & 74,990 & 73,803 & 59,825 \\
\hline
\end{tabular}

$C H D$ coronary heart disease, $C V E$ cardiovascular event, $S D$ standard deviation

respectively, for the second year post-CVE. Differences in costs between studies are likely due to differing risk definitions, health plan inclusion, and propensity scoring strategies.

In summary, previous claims studies have shown that patients having CVEs incur substantially greater costs than those with no CVE, even among varying datasets with differing inclusion criteria. These costs were largely driven by inpatient utilization. This study demonstrating continuing economic burden of CVEs over time in patients with hyperlipidemia is supported by previous findings. Furthermore, this research provides a valuable base to support future studies on the impact of lipid-lowering medications and predicting costs projected over longer time periods.

\section{LIMITATIONS}

Certain limitations of administrative claims studies should be considered. Misclassification and miscoding are possible and diagnostic codes are not definitive proof of disease. The analytic dataset may be affected by the lack of data not available from claims databases, such as certain lab values, family history and smoking status. Also, retrospective studies are prone to spurious associations attributed to bias by way of confounding variables [29, 31, 32], some of which represent unknown risk factors. However, the propensity scores allowed identification of a sample of patients that was balanced across several demographic and known relevant clinical characteristics. The severity of disease represented by the matching factors may differ for those having and not having a CVE. Finally, the findings in this study are not generalizable to a non-commercially insured population.

\section{CONCLUSIONS}

The costs associated with CVEs among patients with hyperlipidemia are high and remain elevated. The CVE costs are largely driven by inpatient hospitalization in the first 30 days, 


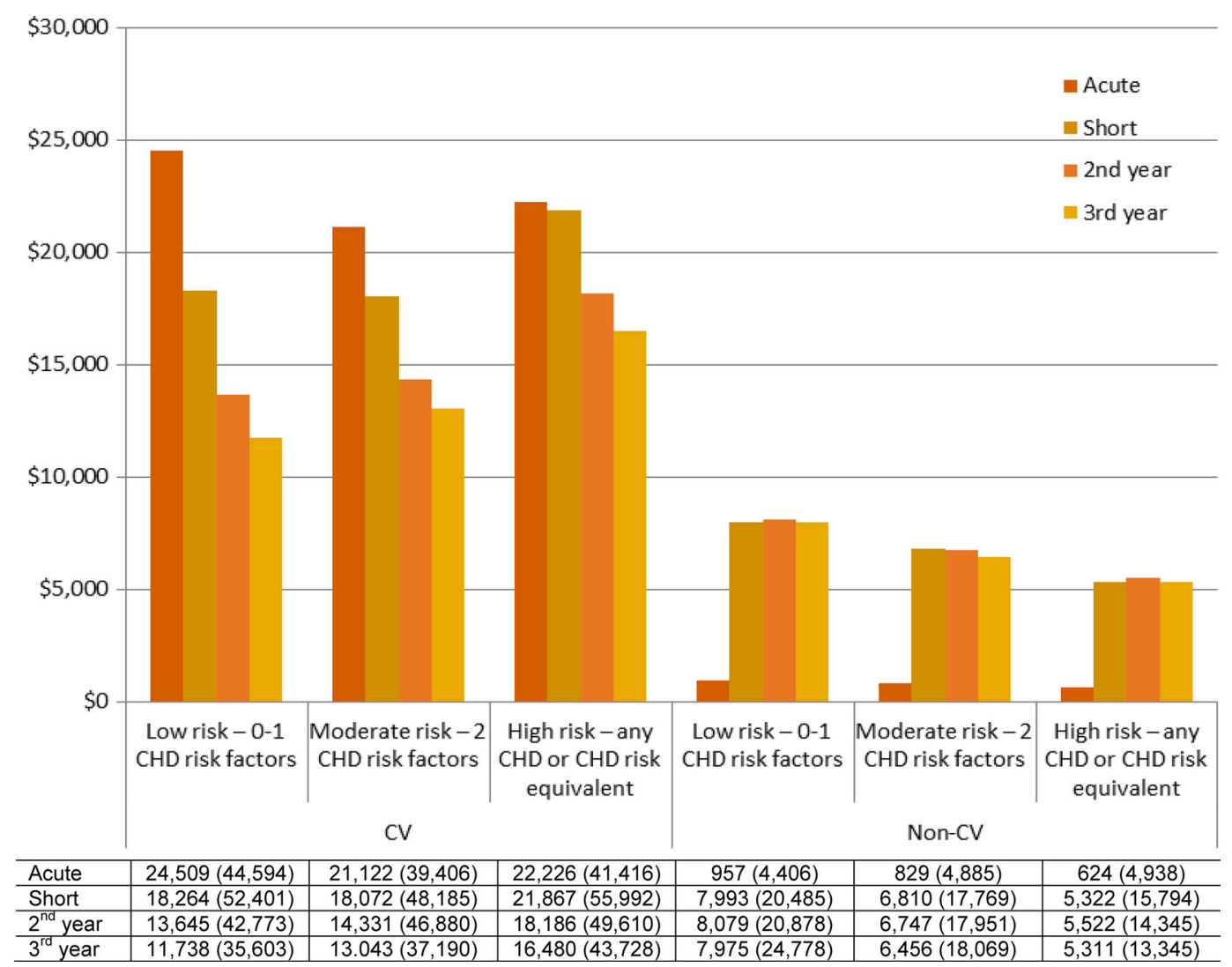

Fig. 2 Mean (standard deviation) costs (in \$USD) following index date for patients experiencing a CVE and in the non-CVE group by CHD risk level in baseline period. $C H D$ coronary heart disease, $C V E$ cardiovascular event

but significant costs persist for several years. After the acute period, outpatient and ambulatory costs represent a larger proportion of costs. The main driver of CVE costs in this study is CHD risk level, with costs varying by index CVE type. To assess the impact of lipid-lowering medications, a similar study including variables on medication use is necessary. Future clinical decision-making and cost-effectiveness studies will benefit from these findings.

\section{ACKNOWLEDGMENTS}

Funding for this study was provided by Amgen Inc. The article processing charges and open access fee for this publication were funded by Amgen Inc. All named authors meet the International Committee of Medical Journal Editors (ICMJE) criteria for authorship for this manuscript, take responsibility for the integrity of the work as a whole, and have given final approval to the version to be published. Medical writing assistance was provided by Caroline Jennermann, an employee of Optum, Inc. Support for this assistance was provided by Amgen Inc.

Disclosures. Carly J. Paoli is an employee of Amgen and holds Amgen stock. Shravanthi R. Gandra is an employee of Amgen and holds Amgen stock. Henry Henk is an employee of Optum, Inc. 
Compliance with ethics guidelines. This article does not contain any studies with human or animal subjects performed by any of the authors.

Open Access. This article is distributed under the terms of the Creative Commons Attribution-NonCommercial 4.0 International License (http://creativecommons.org/licenses/ by-nc/4.0/), which permits any noncommercial use, distribution, and reproduction in any medium, provided you give appropriate credit to the original author(s) and the source, provide a link to the Creative Commons license, and indicate if changes were made.

\section{REFERENCES}

1. Centers for Disease Control and Prevention. Vital signs: prevalence, treatment, and control of high levels of low-density lipoprotein cholesterol-United States, 1999-2002 and 2005-200. MMWR. 2011;60(4):109-14.

2. Delahoy PJ, Magliano DJ, Webb K, Grobler M, Liew D. The relationship between reduction in low-density lipoprotein cholesterol by statins and reduction in risk of cardiovascular outcomes: an updated meta-analysis. Clin Ther. 2009;31(2):236-44.

3. Stauffer ME, Weisenfluh L, Morrison A. Association between triglycerides and cardiovascular events in primary populations: a meta-regression analysis and synthesis of evidence. Vasc Health Risk Manage. 2013;9:671-80.

4. Goff DC Jr, Lloyd-Jones DM, Bennett G, et al. 2013 ACC/AHA guideline on the assessment of cardiovascular risk: a report of the American College of Cardiology/American Heart Association Task Force on Practice Guidelines. Circulation. 2014;129(25 Suppl 2):S49-73.

5. National Center for Health Statistics. Health, United States, 2013: with special feature on prescription drugs. Hyattsville: National Center for Health Statistics; 2013.

6. World Health Organization. The global burden of disease: 2004 update. 2008 Available from: http:// www.who.int/topics/global_burden_of_disease/en/. Accessed 28 Aug 2015.

7. Go AS, Mozaffarian D, Roger VL, et al. Heart disease and stroke statistics-2014 update: a report from the American Heart Association. Circulation. 2014;129(3):e28-292.

8. Chapman RH, Liu LZ, Girase PG, Straka RJ. Determining initial and follow-up costs of cardiovascular events in a US managed care population. BMC Cardiovasc Disorders. 2011;11:11.

9. Demaerschalk BM, Hwang HM, Leung G. US cost burden of ischemic stroke: a systematic literature review. AJMC. 2010;16(7):525-33.

10. Furie KL, Kasner SE, Adams RJ, et al. Guidelines for the prevention of stroke in patients with stroke or transient ischemic attack: a guideline for healthcare professionals from the american heart association/ american stroke association. Stroke; Journal Cerebral Circ. 2011;42(1):227-76.

11. Godwin KM, Wasserman J, Ostwald SK. Cost associated with stroke: outpatient rehabilitative services and medication. Topics Stroke Rehab. 2011;18(Suppl 1):676-84.

12. Smith SC Jr, Benjamin EJ, Bonow RO, et al. AHA/ ACCF secondary prevention and risk reduction therapy for patients with coronary and other atherosclerotic vascular disease: 2011 update: a guideline from the American Heart Association and American College of Cardiology Foundation endorsed by the World Heart Federation and the Preventive Cardiovascular Nurses Association. J Am Coll Cardiol. 2011;58(23):2432-46.

13. Hayes J, Vogel B, Reker DM. Factors associated with VHA costs of care for first 12 months after first stroke. J Rehab Res Dev. 2008;45(9):1375-84.

14. Zorowitz RD, Chen E, Tong KB, Laouri M. Costs and rehabilitation use of stroke survivors: a retrospective study of Medicare beneficiaries. Topics Stroke Rehab. 2009;16(5):309-20.

15. Nichols GA, Bell TJ, Pedula KL, O'Keeffe-Rosetti M. Medical care costs among patients with established cardiovascular disease. Am J Managed Care. 2010;16(3):e86-93.

16. Straka RJ, Liu LZ, Girase PS, DeLorenzo A, Chapman $\mathrm{RH}$. Incremental cardiovascular costs and resource use associated with diabetes: an assessment of 29,863 patients in the US managed-care setting. Cardiovasc Diabetol. 2009;8:53.

17. Doan QV, Gleeson M, Kim J, Borker R, Griffiths R, Dubois RW. Economic burden of cardiovascular 
events and fractures among patients with end-stage renal disease. Curr Med Res Op. 2007;23(7):1561-9.

18. Duh MS, Fulcher NM, White LA, et al. Costs associated with cardiovascular events in patients with hypertension in US managed care settings. J Am Soc Hypertension. 2009;3(6):403-15.

19. Tung CY, Granger CB, Sloan MA, et al. Effects of stroke on medical resource use and costs in acute myocardial infarction. GUSTO I Investigators. Global utilization of streptokinase and tissue plasminogen activator for occluded coronary arteries study. Circulation. 1999;99(3):370-6.

20. Engel-Nitz NM, Sander SD, Harley C, Rey GG, Shah $\mathrm{H}$. Costs and outcomes of noncardioembolic ischemic stroke in a managed care population. Vasc Health Risk Manag. 2010;6:905-13.

21. O'Sullivan AK, Rubin J, Nyambose J, Kuznik A, Cohen DJ, Thompson D. Cost estimation of cardiovascular disease events in the US. Pharmacoeconomics. 2011;29(8):693-704.

22. Punekar RS, Fox KM, Richhariya A, et al. Burden of first and recurrent cardiovascular events among patients with hyperlipidemia. Clin Cardiol. 2015;38(8):483-91.

23. Department of Health and Human Services. Code of Federal Regulations: Protection of human subjects, Code Fed Regul Public Welfare. Title 45 (Sections 46-101 to 46-409). Washington, DC: USDHHS. 1995.

24. Centers for Disease Control and Prevention. International Classification of Diseases, Ninth Revision, Clinical Modification. 2010. Available from: http://www.cdc.gov/nchs/icd/icd9cm.htm. Accessed 28 Aug 2015.

25. Centers for Medicare and Medicaid Services. Healthcare Common Procedure Coding System. Available from: http://www.cms.gov/Medicare/ Coding/MedHCPCSGenInfo/index.html?redirect=/ medhcpcsgeninfo/. Accessed 28 Aug 2015.
26. US Department of Commerce, Economics, and Statistics Administration. US Census Bureau Census Regions and Divisions of the United States. Available at https://www.census.gov/geo/ maps-data/maps/pdfs/reference/us_regdiv.pdf. Accessed 28 Aug 2015.

27. National Cholesterol Education Program Expert Panel on Detection. Evaluation, and treatment of high blood cholesterol in atherosclerosis. third report of the national cholesterol education program (NCEP) expert panel on detection, evaluation, and treatment of high blood cholesterol in adults (Adult Treatment Panel III) final report. Circulation. 2002;106(25):3143-421.

28. US Department of Labor Bureau of Labor Statistics. Consumer Price Index. Chained Consumer Price Index for All Urban Consumers (C-CPI-U) 1999-2012, Medical Care. Series ID: SUUR0000SAM. In: Department of Labor Bureau of Labor Statistics, ed. Washington, DC. 2013.

29. Normand ST, Landrum MB, Guadagnoli E, et al. Validating recommendations for coronary angiography following acute myocardial infarction in the elderly: a matched analysis using propensity scores. J Clin Epid. 2001;54(4):387-98.

30. Roberts CS, Gorelick PB, Ye X, Harley C, Goldberg GA. Additional stroke-related and non-stroke-related cardiovascular costs and hospitalizations in managed-care patients after ischemic stroke. Stroke J Cereb Circ. 2009;40(4):1425-32.

31. D'Agostino RB Jr. Propensity score methods for bias reduction in the comparison of a treatment to a non-randomized control group. Stat Med. 1998;17(19):2265-81.

32. Aghemo A, Rumi MG, Colombo M. Pegylated interferons alpha2a and alpha2b in the treatment of chronic hepatitis C. Nat Rev. Gastroenterol Hepatol. 2010;7(9):485-94. 